\title{
Desensitization of the cough reflex by exercise and voluntary isocapnic hyperpnea
}

Federico Lavorini, Giovanni A. Fontana, Elisa Chellini, Chiara Magni, Roberto Duranti and John Widdicombe

J Appl Physiol 108:1061-1068, 2010. First published 21 January 2010;

doi: $10.1152 /$ japplphysiol.00423.2009

You might find this additional info useful...

This article cites 62 articles, 24 of which you can access for free at:

http://jap.physiology.org/content/108/5/1061.full\#ref-list-1

Updated information and services including high resolution figures, can be found at:

http://jap.physiology.org/content/108/5/1061.full

Additional material and information about Journal of Applied Physiology can be found at: http://www.the-aps.org/publications/jappl

This information is current as of November 17, 2012. 


\title{
Desensitization of the cough reflex by exercise and voluntary isocapnic
}

\section{hyperpnea}

\author{
Federico Lavorini, ${ }^{1}$ Giovanni A. Fontana, ${ }^{1}$ Elisa Chellini, ${ }^{1}$ Chiara Magni, ${ }^{1}$ Roberto Duranti, ${ }^{1}$ \\ and John Widdicombe ${ }^{2}$ \\ ${ }^{1}$ Department of Internal Medicine, Respiratory Medicine and Cell Therapy, University of Florence, Florence, Italy; \\ ${ }^{2}$ University of London, London, United Kingdom
}

Submitted 22 April 2009; accepted in final form 19 January 2010

\begin{abstract}
Lavorini F, Fontana GA, Chellini E, Magni C, Duranti R, Widdicombe $\mathbf{J}$. Desensitization of the cough reflex by exercise and voluntary isocapnic hyperpnea. J Appl Physiol 108: 1061-1068, 2010. First published January 21, 2010; doi:10.1152/japplphysiol.00423.2009.—Little is known about the effects of exercise on the sensory and cognitive aspects of coughing evoked by inhalation of tussigenic agents. The threshold for the cough reflex induced by inhalation of increasing nebulizer outputs of ultrasonically nebulized distilled water (fog), an index of cough reflex sensitivity, was assessed in twelve healthy humans in control conditions, during exercise and during voluntary isocapnic hyperpnea (VIH) at the same ventilatory level as the exercise. The intensity of the urge to cough (UTC), a cognitive component of coughing, was recorded throughout the trials on a linear scale. The relationships between inhaled fog nebulizer outputs and the correspondingly evoked UTC values, an index of the perceptual magnitude of the UTC sensitivity, were also calculated. Cough appearance was always assessed audiovisually. At an exercise level of $80 \%$ of anaerobic threshold, the median cough threshold was increased from a control value of 0.73 to $2.22 \mathrm{ml} / \mathrm{min}(P<0.01)$, i.e., cough sensitivity was downregulated. With VIH, the threshold increased from 0.73 to $2.22 \mathrm{ml} / \mathrm{min}(P<0.01)$, a similar downregulation. With exercise and VIH compared with control, mean UTC values at cough threshold were unchanged, i.e., control, $3.83 \mathrm{~cm}$; exercise, $3.12 \mathrm{~cm}$; VIH, $4.08 \mathrm{~cm}$. The relationship of the fog nebulizer output/UTC value was linear in control conditions and logarithmic during both exercise and VIH. The perception of the magnitude of the UTC seems to be influenced by signals or sensations arising from exercising limb and thoracic muscles and/or by higher nervous (cortical) mechanisms. The results indicate that the adjustments brought into action by exercise-induced or voluntary hyperpnea exert inhibitory influences on the sensory and cognitive components of foginduced cough.
\end{abstract}

urge to cough

COUGHING CAN BE EVOKED by a variety of inhaled chemicals or by mechanical irritation of the airway mucosa and plays an essential role in protecting the airways from potentially harmful stimuli. Both the central and peripheral neural substrates of coughing have been extensively studied $(7,49,58)$. The present concept of the neurogenic mechanisms for coughing and eupneic breathing holds that the multifunctional respiratory pattern generator undergoes functional reconfiguration to produce cough (7). The sensory endings involved in the mediation of cough are exclusively vagal in origin (65). Although reflex cough must therefore originate in a vagally innervated territory, coughing induced by inhaled tussigenic agents exclu-

Address for reprint requests and other correspondence: G. Fontana, FRCP., Dept. of Internal Medicine, Immunoallergology, Respiratory Medicine and Cell Therapy., Viale GB Morgagni, 8550134 Firenze, Italy, (e-mail: g.fontana @ dac.unifi.it) sively involves laryngeal and tracheobronchial receptors (sensors). The neurophysiology of these sensors has been extensively reviewed, as have been their putative mechanism(s) of activation by aqueous solutions $(23,65)$. The cough reflex exhibits significant plasticity at the sensory and ganglionic levels, as well as at the level of the central nervous system (8, 12). This plasticity usually consists of a sensitization (upregulation) of the reflex, but desensitization (downregulation) may also occur (67). Factors implicated in the modulation of the cough reflex, either enhancing or inhibiting it, have been widely reviewed $(31,32,67)$ and apply to both physiological and pathological conditions.

One aspect of cough that has been neglected is the behavioral; this may seem surprising in view of its importance. Speaking, laughing, deep inspirations and expirations, body vibration, sleep, listening to music, and voluntary control all affect cough sensitivity $(66,67)$, yet there is little scientific evidence about how behavior affects cough and about how cough affects behavior. A recent workshop on the subject (66) was notable for the dominance of anecdote over scientific evidence. Considerable attention has also been devoted to the study of the cognitive components of coughing in humans, particularly the sensation of the urge to cough (UTC) that precedes the appearance of motor cough evoked by tussigenic agents (15-18). These studies emphasize the importance of cortical influences on cough.

Physical activity of various intensities is intrinsically related to everyday life and represents a condition during which profound cardiorespiratory adjustments occur. The adaptive responses to exercise include changes in the pattern of breathing and hyperpnea, activation of airway, lung, and, chest wall receptors, and airway water and heat loss (62). It is well known that humans are able to activate some of these adjustments in a voluntary fashion, which implies involvement of cortical areas of the brain; important recent studies emphasize the role of the cortex in initiating and modulating cough activity (1518). Exercise is also associated with increased sympathetic activity and plasma catecholamine concentrations, manifest by increased cardiac output and airflow, as well as with the release of inhibitory neurotransmitters that are colocalized with norepinephrine in sympathetic nerves (25). Some of these phenomena have been implicated in the genesis of the bronchodilator response that appears during the early phases of exercise in healthy subjects (25) and asthmatics (60); bronchodilatation could influence cough sensitivity at a peripheral (sensor) level. Thus, in theory, all exercise-related adjustments can potentially modulate cough through influences on the neural substrates subserving cough, from sensors to brainstem to cortex. In the literature, however, little information is available regarding the 
effects of exercise on the sensitivity and intensity of cough; furthermore, the available information often appears contradictory. For instance, cough and bronchoconstriction are common features of asthmatic subjects after exercise $(1,2)$, and coughing may also appear in some normal subjects mainly after exercise in cold weather (3). However, questioning athletes provides anecdotal evidence that subjects with cough may find it reduced during exercise, suggesting downregulation $(66,67)$.

The aim of this study was to see whether and how exercise and voluntary isocapnic hyperpnea (VIH) affect the sensitivity of the cough reflex and the sensation of a UTC evoked by ultrasonically nebulized distilled water (fog) inhalation in healthy subjects. Our hypothesis was that exercise and VIH might change cough sensitivity, but we did not anticipate whether they would increase or decrease it or whether they would have similar effects.

\section{MATERIALS AND METHODS}

Subjects. Twelve healthy nonsmoker subjects ( 7 women, 5 men; mean age $26.5 \mathrm{yr}$, range $20-34 \mathrm{yr}$ ), who had coughed in response to preliminary cough challenges with fog, participated in the study. All were physically fit, and most of them (4 women, 4 men) regularly performed noncompetitive sports. Subjects were asked to refrain from strenuous physical exercise on the day before the trials. They had not suffered from recent $(<4 \mathrm{wk})$ respiratory tract infections, and they had arterial blood pressures lower than $140 / 85 \mathrm{mmHg}$ and baseline forced expiratory volume in $1 \mathrm{~s}\left(\mathrm{FEV}_{1}\right)$ greater than $90 \%$ of predicted. All procedures were approved by the AOU Careggi ethics committee and adhered to the recommendations of the Declaration of Helsinki for Human Experimentation. Individual informed consent was obtained after explanation of the procedures, but the purpose of the study was not disclosed.

Cardiorespiratory exercise test. All subjects performed a symptom-limited incremental exercise test using an electronically braked cycle ergometer (Ergometrics 800S; SensorMedics, Yorba Linda, CA). After $6 \mathrm{~min}$ of resting breathing and relaxed load-free pedaling warm-up, subjects started pedaling at a rate of 60 revolutions per min, initially at zero load. Subsequently, the workload was increased in $15-20-W$ steps every minute until exhaustion. Subjects wore a nose clip and breathed through a mouthpiece connected to a mass flowmeter and gas analyzer (VMAX 29c, SensorMedics). The output of $\mathrm{CO}_{2}$, $\mathrm{O}_{2}$ consumption $\left(\dot{\mathrm{V}}_{2}\right)$, end-tidal $\mathrm{CO}_{2}$ tension $\left(\mathrm{PET}_{\mathrm{CO}_{2}}\right)$, tidal volume $\left(V_{\mathrm{T}}\right)$, and respiratory frequency $(f)$ were measured on a breath-bybreath basis at rest and during exercise. Minute ventilation ( $\left.\dot{V}_{\mathrm{I}}\right)$ was subsequently calculated. Oxygen saturation by ear lobe sensor (Ohmeda Biox 3740; Datex-Ohmeda, Madison, WI) and cardiac activity by conventional ECG were monitored throughout the exercise test. Maximum power output ( $\dot{\mathrm{W} m a x}$ ) was defined as the highest level of exercise that could be sustained for $1 \mathrm{~min}$ by the subject. For each subject, the anaerobic threshold was calculated by using the method of Wasserman et al. (63, 64).

Cough challenge. Cough was defined as a forced expiratory effort accompanied by a characteristic sound indicating closure of the glottis (47). Cough was induced $(24,26)$ by inhalation of progressively increasing fog outputs produced by a Mist-O ${ }_{2}$-Gen EN143A ultrasonic nebulizer (Medical Equipment Services, Fulton, IL). The driving flow from the nebulizer was constant at 14 1/min (24). The mass median aerodynamic diameter of aerosol particles, when measured without an interposed valve, was $5.7 \pm 0.1 \mu \mathrm{m}$ (53). Before each cough challenge, the nebulizer jar was filled with $180 \mathrm{ml}$ of distilled water. The nebulizer fog output could be adjusted by means of a potentiometer and monitored as a DC signal on an oscilloscope. In preliminary trials, we determined the actual nebulizer output in $\mathrm{ml}$ of water/min by progressively increasing it in steps corresponding to $5 \%$ of the maximum attainable DC signal. The reproducibility of fog outputs was checked by weighing the nebulizer water content before and after each 1-min nebulization period performed at each subsequent $5 \%$ step. Variances calculated for each set of experiments were homogeneous ( $P=0.49$, Cochran's $C$-test); the relationship between nebulizer output and the corresponding DC signal was analyzed by least-squares regression. The relation fitted with the linear model ( $r=$ $0.95 ; P<0.001)$ and mean nebulizer fog output ( $\mathrm{ml}$ water/min) could be calculated according to the following equation:

nebulizer output $(\mathrm{ml}$ water $/ \mathrm{min})=$

$$
-1.90+0.066 X \% \text { of maximum DC signal }
$$

During cough challenges, all participants breathed through a twoway, nonrebreathing, low-resistance shutter valve (modified Lloyd valve; Warren E. Collins, Braintree, MA). A shutter valve was preferred to conventional spiral-type diaphragm valves to minimize the impact of the valve on the physical characteristics of the aerosol. The expiratory port of the valve was connected to a no. 4 Fleisch pneumotachograph and a flow transducer to record expiratory flow; the inspiratory port of the valve was in series with a 1.7-1 reservoir bottle and the ultrasonic nebulizer (27). The reservoir bottle in the inspiratory line ensured constant aerosol supply with each breath (13). The range of nebulizer outputs used in the present experiments was from $30 \%$ to $100 \%$ of the maximum DC signal; the corresponding amount of nebulized water ranged from (mean values) 0.08 to 4.45 $\mathrm{ml} / \mathrm{min}$. In preliminary runs, we ascertained that, during each 1-min nebulization period, the aerosol temperature did not significantly vary with respect to ambient. Each subject was connected to the valve via a mouthpiece. A nose clip was worn. The inhalation time for each nebulizer output was standardized at $1 \mathrm{~min} ; 2$ to $3 \mathrm{~min}$ of rest were allowed between outputs. The appearance of cough was assessed audiovisually by a trained observer who was experienced in detecting both the characteristic sound and respiratory movements of cough. Occurrence of cough and its frequency were recorded on a data sheet for later compilation.

Cough threshold, an index of sensitivity of the cough reflex (24), was determined as the lowest fog output capable of evoking at least one cough effort during both of two distinct challenges separated by a 30-min time interval. This procedure ensured that the cough recorded was a reflex response to the challenge rather than a random event (24). Once cough threshold had been reached, no higher fog outputs were administered.

Assessment of the UTC. During inhalation of each fog output, the intensity of the sensation of a UTC was rated continuously using a $10-\mathrm{cm}-$ long visual analog scale $(40,41)$. The extremes of the sensation (i.e., "no UTC at all" and "extreme UTC") were represented by the two ends of a visual display. Extreme UTC was explained to each participant as a need to cough impossible to resist. A light could be placed at any point within the display by using a hand-controlled linear potentiometer. Both the display and the potentiometer were 10 $\mathrm{cm}$ in length. Equal distances were meant to represent equal variations in the intensity of the sensation. To assess the intensity of the UTC, subjects were recommended to ignore other sensations and were told that their sensation of a UTC could increase, decrease, or stay the same during the fog challenge and that their use of the visual analog scale should reflect this. No verbal cues were given as to when ratings were to be made. Subjects were also requested to concentrate on their sensation during challenges and to adjust the scale accordingly by sliding the potentiometer in a direction toward or away from their body to rate an increase or a decrease in the sensation, respectively. With this method, the distance in centimeters indicated by the light on the visual display represented the intensity of the UTC.

Protocol. Subjects attended the laboratory on four distinct occasions separated by 2-3-day intervals. For logistical reasons, the time intervals could not be the same for all subjects.

On the first study day, subjects were initially requested to perform the incremental exercise test according to the criteria described above; 
this allowed assessment of the anaerobic threshold (64). Following the completion of the exercise test, subjects were allowed to rest for $3 \mathrm{~h}$; subsequently, they were requested to sit again on the cycle ergometer and, after a 6-min warm-up period of free pedaling at zero load, to pedal at a rate of 60 revolutions per min and at a work load corresponding to $80 \%$ of the anaerobic threshold $\left(\dot{\mathrm{W}} 80_{\mathrm{Th}}\right)$. All subjects were able to sustain this exercise intensity for at least $20 \mathrm{~min}$, during which values of $V_{\mathrm{T}}$, and $f$ were continuously recorded on a breath-by-breath basis. No cough challenge was performed on the first study day.

On the subsequent three study days, cough threshold was assessed in each subject according to different and randomly selected experimental protocols. On one occasion, cough threshold was assessed in control conditions, i.e., with the subject comfortably seated on a dentist's chair. On another occasion, cough threshold was similarly assessed but with the subject pedaling at $\dot{\mathrm{W}} 80_{\mathrm{Th}}$. On a further occasion, each subject was seated in a dentist's chair, and cough threshold was assessed during VIH with near identical $V_{\mathrm{T}}$ and $f$ as those attained during pedaling at $\dot{\mathrm{W}} 80_{\mathrm{Th}}$. Allocation of each participant to one of the three experimental protocols was obtained by means of a web site randomization software (http://www.randomization. com). For VIH, the selected depth and rate of breathing were dictated by a signal displayed on an oscilloscope and a metronome, respectively, and were monitored by means of a calibrated (56) respiratory inductive plethysmograph (noninvasive monitoring system; Respitrace Ardsley, NY); the amount of inspiratory $\mathrm{CO}_{2}$ was adjusted manually with the target $\mathrm{PET}_{\mathrm{CO}_{2}}$ (Datex; Normocap, Helsinki, Finland) set at the resting eupneic level. Possible changes in airway caliber provoked by fog inhalation, exercise, and VIH were monitored by $\mathrm{FEV}_{1}$ measurements before and after the test periods.

Data analysis. Values of $V_{\mathrm{T}}$ and $f$ recorded on the first study day during the last $30 \mathrm{~s}$ of pedaling at $\dot{\mathrm{W}} 80_{\mathrm{Th}}$ were averaged, and the obtained mean values were subsequently used to establish the depth and rate of breathing each subject had to match during VIH trials. As stated above, cough threshold was always determined following two fog challenges separated by a 30-min interval (24). The numbers of expiratory efforts recorded during the two 1-min inhalation challenges required to assess the threshold fog output were averaged and taken as a single value for all subsequent calculations. Values of the time to onset (TTO), i.e., the time (in s) elapsed from the beginning of fog inhalation and the appearance of the first cough effort, and of the UTC recorded at cough threshold level were similarly treated. Comparisons of cough threshold, cough number, TTO, and UTC values at cough threshold levels determined in control conditions, during exercise, and VIH were performed by using nonparametric analysis of variance followed by Dunn's multiple-comparisons tests. The same statistical procedure was used to compare breathing pattern variables recorded at threshold stimulus intensity for the cough reflex in control conditions, during exercise, and during VIH.

An attempt was also made at estimating the amount of water inhaled at threshold level for the cough reflex in each subject during each challenge. To this end, we reasoned that the amount of inhaled water must be a function of the following variables: the threshold fog output, the driving force of the nebulizer, and the level of minute ventilation specifically attained during the time period elapsed between the beginning of a cough challenge and the appearance of cough, i.e., the TTO (see above). The amount of water inhaled by each subject was therefore taken as:

$$
\text { (fog output/nebulizer's driving flow) } \times\left(V_{\mathrm{T}}^{\prime \prime} \times f^{\prime \prime}\right)
$$

where the driving flow is constant at $14 \mathrm{l} / \mathrm{min}$ (see above), and $V_{\mathrm{T}}^{\prime \prime}$ and $f^{\prime \prime}$ are the mean values of tidal volume and respiratory rate calculated by averaging all breaths recorded during the TTO.

Comparisons between estimated amounts of inhaled distilled water at the threshold level in each experimental condition were performed by means of repeated-measures analysis of variance followed by Bonferroni multiple-comparisons tests.
In all experimental conditions, the UTC threshold, an index of the cognitive threshold for the UTC, was measured as the fog output that elicited a greater than zero visual analog scale score magnitude estimation of a UTC $(17,18)$. Comparisons between threshold values for cough and UTC were performed by using nonparametric analysis of variance followed by Dunn's multiple-comparisons tests. To investigate the relationship between each inhaled quantity of fog water and the perceptual magnitude of the evoked UTC, individual UTC values recorded during challenges performed in control conditions, during exercise, and during VIH were plotted against the corresponding nebulizer fog water output. Scrutiny of results revealed that relationships between inhaled fog outputs and values of the perceptual magnitude of the UTC in the different experimental conditions fitted linear or nonlinear regression models. Linear regression by the leastsquares method and nonlinear (logarithmic) regression were therefore used to analyze the relationship between data recorded in control conditions, during exercise, and during VIH, respectively. All reported values are means $\pm \mathrm{SD}$, unless otherwise stated; $P<0.05$ was taken as significant. Statistical analyses were carried out by using GraphPad Prism version 5.02 (GraphPad Software, San Diego, CA).

\section{RESULTS}

Mean ( \pm SD) values of cardiopulmonary variables recorded at baseline and during steady-state exercise on the first study day are reported in Table 1. All subjects displayed normal (maximal $\mathrm{VO}_{2}>90 \%$ of predicted) exercise capacity (63); the observed mean $\dot{\mathrm{W}} \max$ and $\dot{\mathrm{W}} 80_{\text {Th }}$ values were $160 \pm 41 \mathrm{~W}$ and $88.6 \pm 14.9 \mathrm{~W}$, respectively. None of the subjects had symptoms of bronchoconstriction or a reduction in arterial blood oxygen saturation during exercise; fog inhalation caused no significant change in postexercise and post-VIH FEV 1 in any of the participants. Cough threshold values ranged from 0.40 to $2.35 \mathrm{ml} / \mathrm{min}$ (median $0.73 \mathrm{ml} / \mathrm{min}$ ) in control conditions, from 1.31 to $4.45 \mathrm{ml} / \mathrm{min}$ (median $2.22 \mathrm{ml} / \mathrm{min} ; P<$ 0.01 ) during exercise, and from 0.73 to $4.45 \mathrm{ml} / \mathrm{min}$ (median $2.22 \mathrm{ml} / \mathrm{min} ; P<0.01)$ during VIH. Median cough threshold values recorded during exercise and VIH did not significantly differ (Fig. 1A). The mean estimated amounts of distilled water inhaled by participants at cough threshold in control conditions, during exercise, and during VIH were $0.33 \pm 0.33 \mathrm{ml}$, $1.38 \pm 1.10 \mathrm{ml}$, and $1.59 \pm 1.45 \mathrm{ml}$, respectively (Fig. 2). Values recorded during exercise and VIH were similar and significantly $(P<0.05)$ higher than those of control conditions (Fig. 2). Mean cough number values recorded in control conditions $(1.57 \pm 1.20)$, during exercise $(1.60 \pm 2.07)$, and during VIH $(2.00 \pm 1.65)$ did not significantly differ. The mean TTOs from start of aerosol administration were $24.30 \pm$ $5.10 \mathrm{~s}$ in control condition, $15.00 \pm 13 \mathrm{~s}$ during $\dot{\mathrm{W}} 80_{\mathrm{Th}}$, and

Table 1. Cardiopulmonary variables recorded in control conditions and during exercise at $\dot{W} 80_{T h}$ on study day 1

\begin{tabular}{lrr}
\hline \hline & \multicolumn{1}{c}{ Control } & \multicolumn{1}{c}{ 'ं80 } \\
\hline$V_{\mathrm{Th}}, 1$ & $0.60(0.13)$ & $1.55(0.14)^{*}$ \\
$f$, breaths/min & $13.71(2.42)$ & $22.85(8.15)^{*}$ \\
$\dot{\mathrm{V}} \mathrm{I}, 1 / \mathrm{min}$ & $8.62(1.51)$ & $32.99(6.38)^{*}$ \\
$\dot{\mathrm{V}} \mathrm{O}_{2}, 1 / \mathrm{min}$ & $0.26(0.03)$ & $1.05(0.27)^{*}$ \\
$\dot{V}_{\mathrm{CO}_{2}}, 1 / \mathrm{min}$ & $0.23(0.03)$ & $0.98(0.10)^{*}$ \\
$\mathrm{HR}$, beats/min & $83.5(2.47)$ & $127.66(8.23)^{*}$ \\
\hline
\end{tabular}

Values are means $(\mathrm{SD})(n=12)$. $\dot{\mathrm{W}} 80_{\mathrm{Th}}$, constant load corresponding to $80 \%$ of the anaerobic threshold; $V_{\mathrm{T}}$, tidal volume; $f$, respiratory frequency; $\dot{\mathrm{V}}_{\mathrm{I}}$, inspiratory minute ventilation; $\dot{\mathrm{V}}_{2}$, oxygen consumption; $\dot{\mathrm{V}}_{\mathrm{CO}_{2}}$, carbon dioxide production; HR, heart rate; $* P<0.01$ compared to control condition. 

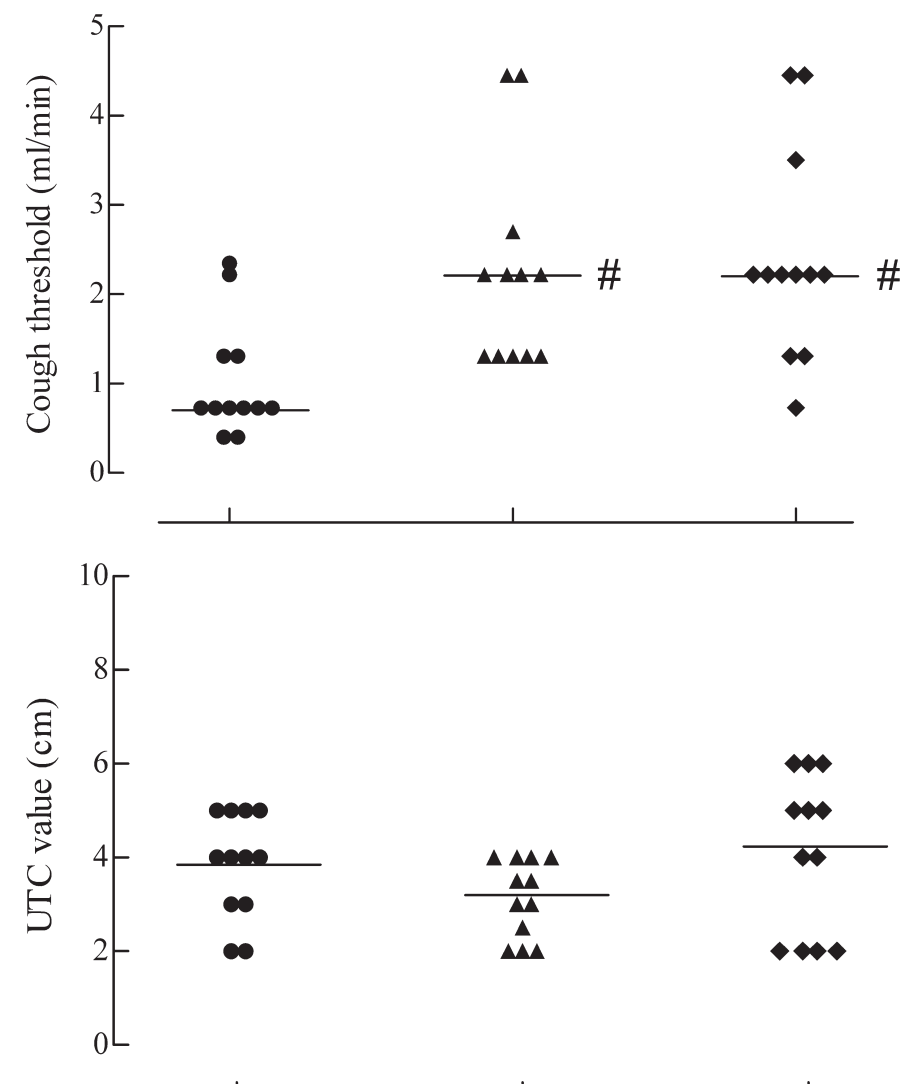

Fig. 1. Comparisons between threshold values for the cough reflex (top) and the urge to cough (UTC) values (bottom) attained at cough threshold in control conditions (-), during exercise at a constant work load corresponding to $80 \%$ of the anaerobic threshold $\left(\dot{\mathrm{W}} 80_{\mathrm{Th}}, \boldsymbol{\Delta}\right)$, and during voluntary isocapnic hyperpnea $(\diamond)$ performed with the same tidal volume and respiratory rate values as those attained during exercise at $\dot{W} 80_{\text {Th }}$. Each symbol corresponds to a single subject; horizontal lines are median values. $\# P<0.01$.

$+16.00 \pm 11.78 \mathrm{~s}$ during VIH. There was no significant difference between these times. Mean values of breathing pattern variables recorded in control conditions, during exercise, and during VIH are given in Table 2. During exercise and $\mathrm{VIH}, \dot{\mathrm{V}}_{\mathrm{I}}, V_{\mathrm{T}}$ and $f$ were significantly $(P<0.01)$ greater than in control conditions; there were simultaneous increases in both $V_{\mathrm{T}}$ and $f$.

As previously reported (41), fog inhalation in normal subjects is consistently accompanied by significant increases in $\dot{\mathrm{V}}_{\mathrm{I}}$ attributable to prominent increases in $V_{\mathrm{T}}$. These changes in the pattern of breathing induced by inhalation of progressively increasing fog outputs during control challenges are depicted in Fig. 3. During exercise and VIH, similar increases in $V_{\mathrm{T}}$ and $f$ were not seen (data not included, see DISCUSSION).

In all experimental conditions, inhalation of fog at the smallest output $(0.08 \mathrm{ml} / \mathrm{min})$ caused no respiratory sensation in any of the subjects, independently of the experimental condition. The threshold fog output to elicit a UTC greater than zero was $0.4 \mathrm{ml} / \mathrm{min}$ in 10 out of the 12 subjects and 0.73 $\mathrm{ml} / \mathrm{min}$ in the remaining two. In each individual subject and for each experimental condition, the threshold UTC value was always lower than the corresponding cough threshold value; in consequence, the corresponding mean threshold values for UTC and cough differed significantly $(P<0.01)$. At threshold

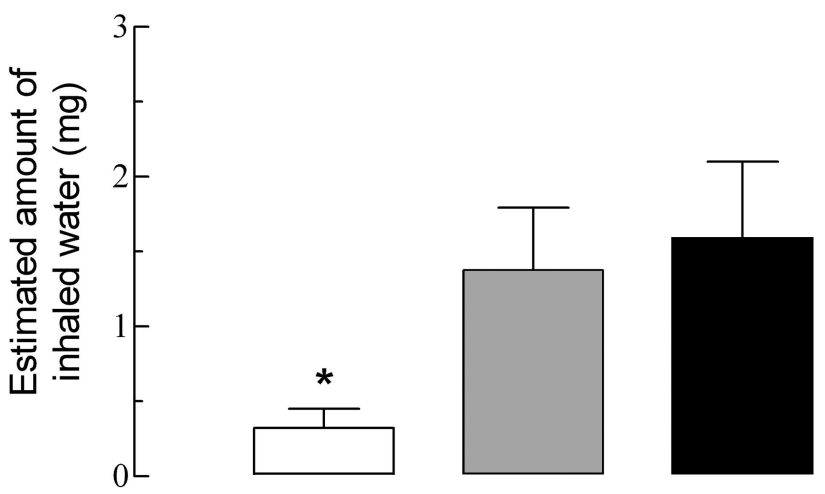

Fig. 2. Means \pm SD of estimated amount of distilled water inhaled by the subjects at threshold stimulus intensity for the cough reflex in control conditions (open bar), during exercise at a constant work load corresponding to $80 \%$ of the anaerobic threshold (shaded column), and during voluntary isocapnic hyperpnea (solid column). The variables used for estimating the amount of inhaled distilled water in each subject are the ventilation, the fog output, and the driving flow of the nebulizer (see MATERIALS AND METHODS). $* P<0.05$ compared with exercise and voluntary isocapnic hyperpnea.

stimulus intensity for the cough reflex, mean UTC values measured in control conditions $(3.83 \pm 1.11 \mathrm{~cm})$, during exercise $(3.12 \pm 0.82 \mathrm{~cm})$, and during VIH $(4.08 \pm 1.67 \mathrm{~cm})$ did not significantly differ (Fig. $1 B$ ).

For each participant and in control conditions, regression analysis revealed that the relationship between each fog output and the magnitude of the perceived UTC at threshold was linear $(r=0.95$, Fig. 4A). Conversely, the relationships between each fog output and the magnitude of the perceived UTC during $\dot{\mathrm{W}} 80_{\mathrm{Th}}$ and $\mathrm{VIH}$ better fitted a nonlinear (logarithmic) relationship $(r=0.88$ and $r=0.92$, respectively, Fig. $4, B$ and $C$ ).

\section{DISCUSSION}

The principal findings of this study are that, during steadystate exercise and $\mathrm{VIH}$, the thresholds for evoking the cough reflex and for causing a UTC by fog inhalation are increased, whereas the corresponding strength of the UTC at cough threshold is unchanged (Fig. 1). However, during exercise and $\mathrm{VIH}$, the relationships between UTC and fog output are logarithmic, whereas it is linear in control conditions (Fig. 4). The results may be explained by changes in the various afferent inputs that cause or influence cough or by changes in cough control in the brainstem or the cortex.

We stress that our results apply only during exercise and do not apply to what happens afterward, when bronchial hyperreactivity may occur $(1,2)$. Also our results apply only to healthy unanesthetized human subjects. Francois Marchal et al. (per-

Table 2. Breathing pattern variables recorded at threshold stimulus intensity for the cough reflex in control conditions, during exercise at $\dot{W} 80_{T h}$, and during VIH

\begin{tabular}{lrrr}
\hline \hline & \multicolumn{1}{c}{ Control } & \multicolumn{1}{c}{ फं80 } & \multicolumn{1}{c}{ VIH } \\
\hline$V_{\mathrm{T}}, 1$ & $0.74(0.09)$ & $1.60(0.26)^{*}$ & $1.47(0.32)^{*}$ \\
$f$, breaths/min & $13.25(2.05)$ & $22.80(7.83)^{*}$ & $24.43(4.58)^{*}$ \\
VI, $1 / \mathrm{min}$ & $10.20(1.30)$ & $33.80(5.45)^{*}$ & $34.71(4.50)^{*}$ \\
\hline
\end{tabular}

Values are means $(\mathrm{SD})(n=12)$. VIH, voluntary isocapnic hyperpnea. $* P<0.01$ compared to control condition. 


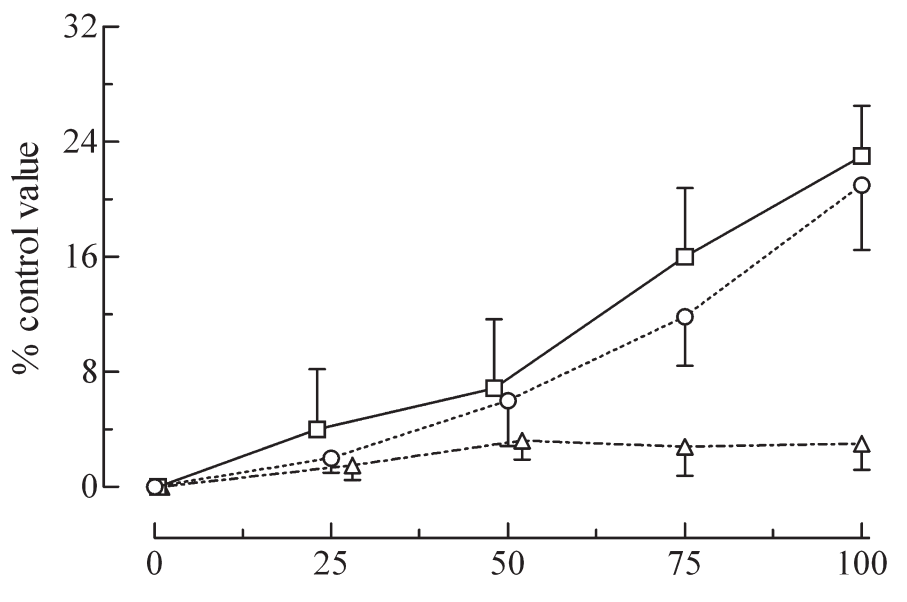

Fog output ( $\%$ threshold output)

Fig. 3. Mean $(n=12)$ changes in breathing pattern variables recorded in control conditions during inhalation of progressively increasing fog outputs up to the threshold level $(100 \%)$. $\square$, tidal volume; $\bigcirc$, minute ventilation; $\triangle$, respiratory rate. Bars represent $\mathrm{SD}$

sonal communication) have found that electrically stimulated muscular contractions in anesthetized rabbits increase the cough response to mechanical stimulation of the trachea. Dehghani al al. (20) found that patients with left ventricular dysfunction coughed during exercise, unlike healthy controls. At high altitude the incidence of cough seems to be related to exercise, but it has not been shown that exercise triggers or intensifies the cough (46). We can find no other relevant references although a recent workshop (66) discussed the subject but provided no documented evidence related to it. Similarly the effect of VIH on cough sensitivity does not seem to have been studied (6).

The mechanism of airway sensory receptor stimulation by low $\left[\mathrm{Cl}^{-}\right]$solutions remains poorly defined. Water-sensitive airway nerves are, for most part, mechanosensitive; thus it seems plausible that the response to water and nonisosmotic solutions is simply a response to mechanical deformation of the epithelium (cell shrinkage or swelling), in turn acting on the neural membrane (23). It has also been suggested that receptor membranes have specific $\mathrm{Cl}^{-}$binding sites that might have to be occupied to stabilize the nerve $(5,30)$. Removal of $\mathrm{Cl}^{-}$ might increase the conductance to other ions, notably $\mathrm{Na}^{+}$, with subsequent depolarization and generation of an action potential (23). Indeed, at the laryngeal epithelial level, blocking of the $\mathrm{Na}^{+}$channels reduces responsiveness of a subgroup of water-sensitive endings (33). More simply, it may be that the $\left[\mathrm{Cl}^{-}\right]$inside the nerve falls proportionately with decreases in $\left[\mathrm{Cl}^{-}\right]$of the surrounding solution. This would result in nerve depolarization with a mechanism similar to that observed in skeletal muscle fibers (33).

Many of the adaptive responses evoked by exercise can be largely mimicked by voluntary hyperpnea, and most of them have the potential to modulate cough sensitivity, either by upregulating or downregulating it. The overall reduction in cough sensitivity observed in our experiments must therefore represent the net effect of potentially contrasting influences brought into action by augmented breathing, either induced by exercise or by $\mathrm{VIH}$, on the mechanisms regulating cough sensitivity.

The outcomes of bronchial challenges are influenced by technical and nontechnical factors including aerosol temperature, the presence of a valve and mouthpiece, the subject's inspiratory flow rate, and airway caliber. In previous studies $(24,26)$, we tried to standardize our method for cough induction. More precisely, we managed to determine the amount of water aerosol produced by our nebulizer at every selected power output, as well as to demonstrate the short- and longterm reproducibility of our cough threshold measurements (24, 26). We have used the nebulizer output of water aerosol to determine cough threshold. We are aware that, in the present experiments, the increased flow rate achieved by the participants during hyperpnea may have affected the dose and the deposition of the aerosols, thus ultimately influencing the observed cough threshold. However, previous studies (53), performed with the same ultrasonic nebulizer as that in the present study, show that, when operated for $1 \mathrm{~min}$ at flow rates similar to those attained voluntarily or because of exercise by our subjects, the nebulizer output was not significantly affected, even in the presence of tubing and a respiratory valve.

Previous studies $(4,9,11)$ have demonstrated that, when the inspiratory flow rate is increased, the ratio of central-to-peripheral distribution of deposited aerosol is larger, pointing to a
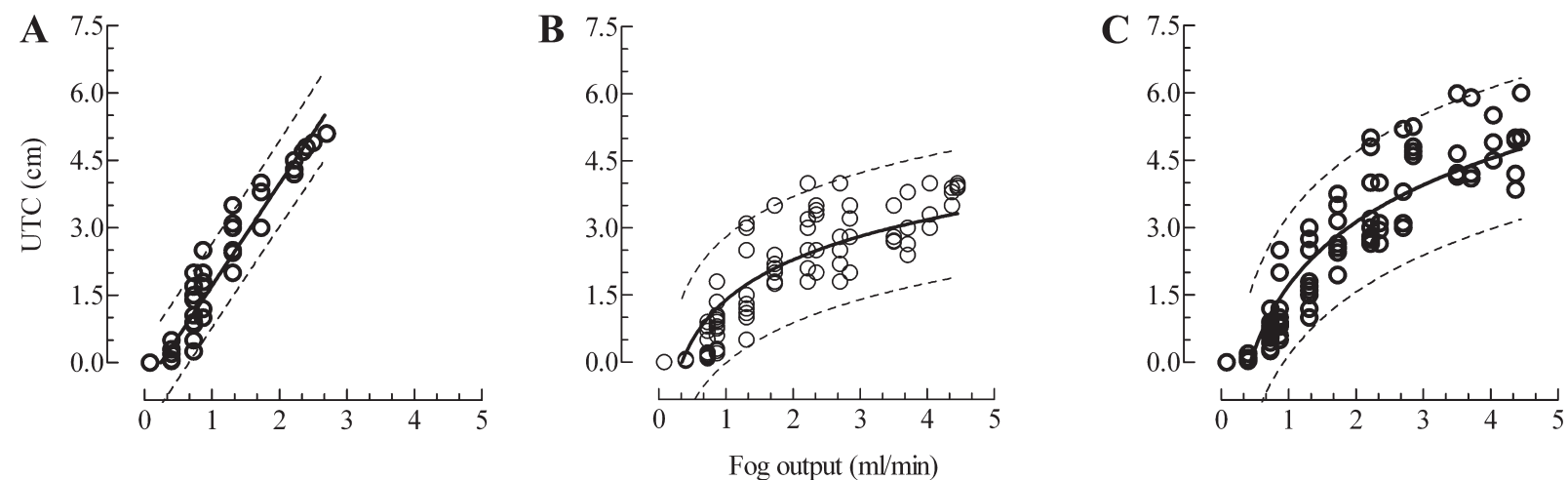

Fig. 4. Relationships between inhaled fog outputs and the corresponding UTC values expressing the perceptual cough sensitivity at threshold in control conditions $(A)$, during exercise at a constant work load corresponding to $80 \%$ of the anaerobic threshold $(B)$, and during voluntary isocapnic hyperpnea $(C)$ in 12 normal subjects. Note that the relationships (solid lines) fit the linear model in control conditions and the logarithmic model during hyperpnea of either origin. The greater number of data points in $B$ and $C$ is due to the larger number of fog outputs needed to determined cough threshold in these experimental conditions. Dashed lines represent the $95 \%$ prediction bands, i.e., the area that should enclose $95 \%$ of future data points. 
possibility that the increased respiratory drive of hyperpnea might favor a more central deposition of the aerosol. Interestingly, neuroanatomical and physiological studies have consistently shown that the majority of airway sensors putatively involved in cough mediation are located in the proximal portions of the tracheobronchial tree $(57,65)$. Our results show that, at the threshold level for the cough reflex, the estimated amounts of distilled water inhaled during the 1-min cough challenges were significantly lower in control conditions compared with during exercise and VIH. Therefore, during hyperpnea in either condition, not only was the amount of fog that reached subjects' airways significantly higher than in control conditions, but also the fog must have deposited more centrally in the airways, i.e., where the cough receptors have been located $(57,65)$. Conceivably, for any given level of $\dot{V}_{\mathrm{I}}$, an increase in the amount of inhaled water with more central deposition within the airways should result in a higher cough stimulus strength. Therefore, the fact that cough threshold assessed by nebulizer output during exercise and VIH was actually increased compared with control conditions not only shows a downregulation of cough sensitivity but also that the downregulation might have been even greater if the actual input of aerosol into the lungs had been given as the stimulus.

Possibly the aerodynamic properties of inhaled aerosol particles may have varied by changing the power output at which the nebulizer was operated. However, because in all instances the output was progressively augmented to produce the same sequence of increasing stimulus strengths (see $E q .1$ ), we are confident that the aerosol aerodynamic properties did not vary significantly between subjects and experimental sessions, thus making it unlikely to have represented a confounding factor.

Exercise causes bronchodilatation in animals $(44,45)$ and humans (25), and, because this can be induced by skeletal muscle contraction in an occluded limb (54), the effect must be largely reflex. Exercise, even at submaximal intensities, is also associated with augmented sympathetic activity, leading to an increase in catecholamine plasma concentrations (25), as well as to the release of inhibitory nonepinephrinergic, noncholinergic neurotransmitters that are colocalized with norepinephrine in sympathetic motor nerves (25). All these substances have been implicated in the bronchodilatation of exercise (see Ref. 25). Because bronchoconstriction enhances the cough reflex (65), it seems plausible that bronchodilatation would inhibit it. However, contrary to this possibility, bronchodilatation by procaterol proved to have no direct effect on cough threshold in human subjects (29). More importantly, it is worth recalling that none of the subjects studied here displayed any significant change in $\mathrm{FEV}_{1}$ after exercise and VIH.

A main difference between the hyperpnea of exercise and that performed voluntarily is that, in the latter, afferents from muscles and joints (other than those from the chest wall and diaphragm) are not activated. Afferents from contracting skeletal muscles cause reflex bronchodilatation (see above), but the fact that, in exercise and VIH, the increases in cough threshold were almost identical seems to rule this out as a possible mechanism.

Javorka et al. (36) showed with rabbits that chest wall vibration inhibits breathing and reduces the intensity of cough, especially the inspiratory component, induced by mechanical stimulation of the larynx and trachea. In humans, vibrations over the seventh to tenth intercostal spaces reduce the volume and time components of breathing (34) and also reduce the cough response to inhaled citric acid (39). These mechanisms could contribute to our results with both exercise and VIH.

Augmented breathing increases the activity of slowly adapting pulmonary stretch receptors (SARs), which respond to lung volume increases $(57,65)$. The effect of SAR activation on the strength of the cough reflex has been studied with diverse findings. Some studies, including with humans, showed that lung inflation augmented the strength of the cough reflex (50, 51). Conversely, in anesthetized animals, lung volume increases caused by continuous positive airway pressure decreased the strength of the cough reflex (37). Other studies gave a negative result (55). However, these experiments assessed the strength of the cough reflex and not its sensitivity to tussigenic stimuli. Therefore, the role played by putative activation of mechanosensitive lung sensors on cough sensitivity to fog inhalation remains to be clarified. Exercise also increases cardiac output and pulmonary blood flow and, to a lesser extent, so does hyperpnea (14). This stimulates pulmonary $\mathrm{C}$-fiber sensors $(52,65)$. Although it had earlier been suggested that activation of these nerve endings could cause cough, this view has been refuted with the demonstration that they inhibit cough (61). Therefore they might increase the threshold to tussigenic stimuli. In theory, increased ventilation might increase the activity of airway cough sensors such as those recently described in guinea pigs (10). However, the presence of such receptors in other animal species has not yet been documented; furthermore, cough sensors seem in general rather insensitive to airway distending pressure (10) so that their activation by the increased breaths of hyperpnea seems unlikely.

Coughing and breathing are generated by the same brainstem neuronal substrates $(7,49,58)$; in consequence, when a tussigenic stimulus is imposed during exercise or $\mathrm{VIH}$, the respiratory controller must give priority to the production of the motor pattern that is specific to either behavior, according to the prevailing need $(7,62 \mathrm{a})$. Therefore, it can be speculated that the increased metabolic demands of exercise and the cortically generated motor command of voluntary hyperpnea may engage the respiratory pattern generator in increasing respiratory activity with a diminished response on the cough motor pattern. In consequence, a cough stimulus of sufficient intensity to evoke cough in a given subject during resting breathing may no longer be effective when the respiratory neurons are required to produce the increased breathing of voluntary and exercise-induced hyperpnea, i.e., when the need of breathing prevails. In other words cough will be downregulated at the expense of hyperpnea.

Hyperpnea of any origin may, depending on the environmental conditions, also result in respiratory heat and water loss, which have been shown to cause, respectively, bronchoconstriction in patients with asthma (19) and coughing in some healthy subjects (4). However, it seems unlikely that either heat or water loss had any relevant role in the present experiments in which inspired air was invariably fully saturated and at room temperature.

"Distraction," in the form of meditation or music can inhibit cough $(35,59)$ and, except for music, could have had a role in our results. Voluntary suppression of cough seems implausible because the subjects had no reason to do this. Distraction also inhibits the sensation of UTC (16) so that the subjects may 
have been distracted by awareness that they were exercising or voluntarily increasing their breathing. The fact that both the thresholds to cough and the UTC attributable to water aerosol were equally increased by exercise strongly implies that the cortex plays a major role in the described responses. Whether focusing the subject's attention on a specific exercise task or on achieving a predetermined level of voluntary hyperpnea also contributed to heightening cough and UTC thresholds remains to be clarified. There are similarities between our results and those relating to dyspnea and pain, both of which have been extensively studied (e.g., 16, 42, 43).

We also attempted to evaluate whether and to what extent exercise-induced and voluntary hyperpnea influence the perceptual magnitude and sensitivity of the UTC evoked by fog inhalation in normal subjects. We acknowledge that the intensity of the fog stimulus in the present experiments was varied in an ascending way, thus predisposing the subjects to always expect the next stimulus to be greater then the previous one, although this was not told to the subject. This possible anticipatory bias could have affected the assessment of UTC (17). To overcome this, an obvious alternative would be to administer fog outputs in random order. However, it has been demonstrated that fog-induced cough is subjected to a high degree of adaptation (48). Thus administration of a suprathreshold fog stimulus is likely to prevent coughing in response to a subsequent weaker stimulus, even if the latter would have sufficed if administered in reverse order. With this in mind, we thought that the use of progressively increasing fog outputs would minimize the risk that random adaptation would complicate the interpretation of results. Whether adaptation also interferes with the perception of a UTC during fog challenges remains to be ascertained. In addition, it seems worth mentioning that assessments of respiratory sensations such as dyspnea during administration of stimuli of ascending intensity, for example the bronchoconstrictive agent methacholine (38) and incremental exercise (43), are commonly preferred methods. The relative merits of ascending and random strengths of stimuli to cause cough have been discussed in detail $(21,28)$.

As with capsaicin $(17,18)$, also with fog the UTC threshold proved to be consistently lower than the cough threshold, in keeping with the view that the UTC precedes motor cough (17, 18). This may allow the subject to voluntarily modify cough before the cough occurs. We also observed that, in all experimental conditions, the average magnitude estimation of the UTC threshold level (Fig. 1) is about 3-4, and that cough never occurs for UTC magnitude estimations less than 2. To the best of our knowledge, the present results are the first to show that, during fog challenges, the threshold for UTC is consistently lower than the threshold for motor cough, a finding strictly in keeping with those of previous capsaicin studies (17). Therefore, it is tempting to conclude that the sensory pathways activated by inhaled fog and capsaicin and mediating the UTC sensations are similar in behavior.

In control conditions, we confirmed that inhaled fog causes an increase in ventilation mainly attributable to increased $V_{\mathrm{T}}$ (41) (Fig. 3). This occurs before cough and in general parallels the UTC. This effect may be due to reflex and/or cortical activities influencing ventilation and UTC. The effect was not seen during inhaled fog during exercise or VIH. Had they been of the same size as during controls, they might have been too small to detect during exercise, and the controlled breathing of VIH would prevent their appearance.

In control conditions, we found a linear relationship between the strength of the cough stimulus and the magnitude of the UTC (Fig. 4A). This finding is consistent with previous outcomes obtained by using capsaicin as a tussigenic stimulus (17). Of course this is not a true sensitivity relationship because all points on the graphs are taken from threshold values. A novel finding presented here is that, during exercise and $\mathrm{VIH}$, the relationship between the cough stimulus intensity and the magnitude of the UTC better fits a logarithmic rather than a linear model (Fig. 2, B and $C$ ); it is not clear whether this observation has functional significance. It can be speculated that, during exercise and VIH, neural signals arising from exercising limb and thoracic muscles may limit full perception of UTC or that the involvement of the cortex in the hyperpnea has a similar effect.

In conclusion, we have shown that the complex reflex and nonreflex mechanisms brought into action by exercise and VIH can downregulate the sensitivity of the cough reflex and the perceptual magnitude of the UTC to fog inhalation. Knowledge of the roles played by each of these mechanisms might improve our understanding of the complex sensory and cognitive architecture of the cough reflex.

\section{DISCLOSURES}

No conflicts of interest are declared by the authors.

\section{REFERENCES}

1. Anderson SD. How does exercise cause asthmatic attacks? Curr Opin Allergy Clin Immunol 6: 37-42, 2000.

2. Anderson S, Holzer K. Exercise-induced asthma: is this the right diagnosis in elite athletes? J Allergy Clin Immunol 106: 419-428, 2000.

3. Banner AS, Green J, O'Connor M. Relation of respiratory water loss to coughing after exercise. $N$ Engl J Med 311: 883-8866, 1984.

4. Bennet WD, Messina MS, Smaldone GC. Effect of exercise on deposition and subsequent retention of inhaled particles. J Appl Physiol 59: 1046-1054, 1985.

5. Boggs DF, Bartlett D. Chemical specificity of a laryngeal apneic reflex in puppies. J Appl Physiol 53: 455-462, 1982.

6. Bolser DC, Fontana GA. Poster discussion: summary. Pulm Pharmacol Ther 22: 163-165, 2009.

7. Bolser DC, Poliacek I, Jakus J, Fuller DD, Davenport PW. Neurogenesis of cough, other airways defensive behaviors and breathing: a holarchical system? Respir Physiol Neurobiol 152: 255-265, 2006.

8. Bonham AC, Sekizawa SI, Joad JP. Plasticity of central mechanisms of cough. Pulm Pharmacol Ther 17: 453-458, 2004.

9. Bowes 3rd SM, Laube BL, Links JM, Frank R. Regional distribution of inhaled fog droplets: preliminary observations. Environ Health Perspect 79: 151-157, 2001.

10. Canning BJ, Mori N, Mazzone SB. Vagal afferent nerves regulating the cough reflex. Respir Physiol Neurobiol 152: 223-242, 2006.

11. Cardelicchio S, Ferrante E, Castellani W, Panuccio B, Comis G, Boddi V, Fontana GA. Influence of inspiratory flow rate on the bronchial response to ultrasonic mist of distilled water in asthmatic patients. Respiration 56: 220-226, 1989.

12. Carr MA. Plasticity of vagal afferent fibres mediating cough. Pulm Pharmacol Ther 17: 447-452, 2004.

13. Corcoran TE, Dauber JH, Chigier N, Iacono AT. Improving drug delivery from medical nebulizers: the effects of increased nebulizer flow rates and reservoirs. J Aerosol Med 15: 271-282, 2002.

14. Cummin AR, Iyawe VI, Mehta N, Saunders KB. Ventilation and cardiac output during the onset of exercise, and during voluntary hyperventilation, in humans. J Physiol 370: 567-583, 1986.

15. Davenport PW. Urge-to-Cough: what can it teach us about cough? Lung 186: S107-S111, 2008.

16. Davenport PW. Clinical cough I: the urge-to-cough: a respiratory sensation. Hand Exp Pharmacol 187: 263-276, 2009. 
17. Davenport PW, Bolser DC, Vickroy T, Berry RB, Martin AD, Hey JA, Danzig M. The effect of codeine on the Urge-to-Cough response to inhaled capsaicin. Pulm Pharmacol Ther 20: 338-346, 2007.

18. Davenport PW, Sapienza CM, Bolser DC. Psychophysical assessment of the urge-to-cough. Eur Respir Rev 12: 249-253, 2002.

19. Deal EC Jr, McFadden ER Jr, Ingram RH Jr, Strauss RH, Jaeger JJ. Role of respiratory heat exchange in production of exercise-induced asthma. J Appl Physiol 46: 467-475, 1979.

20. Dehghani GA, Parvizi MR, Sharif-Kazemi MB, Raj H, Anand A, Paintal AS. Presence of lobeline-like sensations in exercising patients with left ventricular dysfunction. Respir Physiol Neurobiol 143: 9-20, 2004.

21. Dicpinigaitis PV. Experimentally induced cough. Pulm Pharmacol Ther 20: 319-324, 2007.

23. Fontana GA, Lavorini F, Pistolesi M. Water aerosols and cough. In: Acute and Chronic Cough, edited by Redington AE and Morice AH. Boca Raton, FL, Taylor \& Francis Group, 2005, p. 195-241.

24. Fontana GA, Pantaleo T, Lavorini F, Boddi V, Panuccio P. A noninvasive electromyographic study on threshold and intensity of cough in humans. Eur Respir J 10: 983-989, 1997.

25. Fontana GA, Panteleo T, Lavorini F, Bongianni F, Manelli M, Bridge PD, Pistolesi M. Handgrip-induced airway dilation in asthmatic patients with bronchoconstriction induced by MCh inhalation. J Appl Physiol 93: 1723-1730, 2002.

26. Fontana GA, Pantaleo T, Lavorini F, Maluccio NM, Mutolo D, Pistolesi M. Repeatability of cough-related variables during fog challenges at threshold and suprathreshold stimulus intensity in humans. Eur Respir J 13: 1447-1450, 1999.

27. Fontana GA, Pantaleo T, Lavorini F, Mutolo D, Polli G, Pistolesi M. Coughing in laryngectomized patients. Am J Respir Crit Care Med 160: $1578-1584,1999$

28. Fuller RW. Cough sensitivity and the use of provocation tests. In: Cough: Causes, Mechanisms and Therapy, edited by Chung KF, Widdicombe JG, Boushey HA. Blackwell, Oxford, 2003, p. 49-56.

29. Fujimura M, Sakamoto S, Kamio Y, Matsuda T. Effects of methacholine induced bronchoconstriction and procaterol induced bronchodilation on cough receptor sensitivity to inhaled capsaicin and tartaric acid. Thorax 47: 441-445, 1992.

30. Ghosh TK, Van Scott MR, Mathew OP. Epithelial modulation of afferent nerve endings: differential effects of amiloride on afferent subtypes. J Appl Physiol 78: 2235-2240, 1995.

31. Hanacek J. Reflex inputs to cough. Eur Respir Rev 12: 259-263, 2002.

32. Hanacek J, Tatar M, Widdicombe J. Regulation of cough by secondary sensory inputs. Respir Physiol Neurobiol 152: 282-297, 2006.

33. Hodgkin AL, Horowitz P. Influence of potassium and chloride ions on the membrane potential of single muscle fibers. J Physiol 148: 127-160, 1959 .

34. Homma I. Inspiratory inhibitory reflex caused by chest wall vibration in man. Respir Physiol 39: 345-353, 1980.

35. Johnson CM, Brammar C, Cala R, Jones S, Woodcock AA, Smith JA. The effect of psychological interventions on the cough reflex (Abstract). Thorax 59: 43, 2004.

36. Javorka K, Kulisek V, Calovska A. Defensive reflexes of the respiratory system in anaesthetized rabbits during high frequency ventilation. Exp Physiol 79: 967-973, 1994.

37. Javorka K, Michalik J, Caklos S, Bevilaqua J. Effect of increased intrapulmonary pressure on defensive reflexes of the respiratory tract. Lek List 77: 612-620, 1982.

38. Killian KJ, Watson R, Otis J, St Amand TA, O'Byrne PM. Symptom perception during acute bronchoconstriction. Am J Respir Crit Care Med 162: 490-496, 2000.

39. Kondo T, Kobayshi I, Hayama N, Ohta Y. An increase in the threshold of citric acid-induced cough during chest wall vibration in healthy humans. Jpn J Physiol 48: 341-345, 1998.

40. Lavorini F, Fontana GA, Pantaleo T, Geri P, Piumelli R, Pistolesi M, Widdicombe J. Fog-induced cough with respiratory sensation in congenital central hypoventilation syndrome. Am J Respir Crit Care Med 176: 825-832, 2007.

41. Lavorini F, Pantaleo T, Geri P, Mutolo D, Pistolesi M, Fontana GA. Cough and ventilatory adjustments evoked by aerosolised capsaicin and distilled water (fog) in man. Respir Physiol Neurobiol 156: 331-339, 2007.

42. Leupoldt von A, Taube K, Schubert-Heukeshoven S, Magnussen H, Dahme B. Distractive auditory stimuli reduce the unpleasantness of dyspnea during exercise in patients with COPD. Chest 132: 1506-1512, 2007.
43. Mahler DA, Rosiello RA, Harver A, Lentine T, McGovern JF, Daubenspeck JA. Comparison of clinical dyspnea ratings, and psychophysical measurements of respiratory sensation in obstructive airway disease. Am Rev Respir Dis 135: 1229-1233, 1987.

44. Marchal F, Demoulin B, Schweitzer C, Leblanc AL, Bertin N. Airway response to induced muscular contraction in spontaneously breathing rabbits. Respir Physiol Neurobiol 160: 224-231, 2008.

45. Marchal F, Schweitzer C, Moreau-Colson C. Respiratory impedance response to a deep inhalation in children with a history of cough or asthma. Pediatr Pulmonol 33: 441-448, 2002.

46. Mason NP, Barry PW. Altitude-related cough. Pulm Pharmacol Ther 20: 388-395, 2007.

47. Morice AH, Fontana GA, Belvisi MG, Birring SS, Chung KF, Dicpinigaitis PV, Kastelik JA, McGarvey LP, Smith JA, Tatar M, Widdicombe J. ERS Task Force. ERS Guidelines on the assessment of cough. Eur Respir J 29: 1256-1276, 2007.

48. Morice AH, Higgins KS, Yeo WW. Adaptation of cough reflex with different types of stimulation. Eur Respir J 5: 841-847, 1992.

49. Mutolo D, Bongianni F, Fontana GA, Pantaleo T. The role of excitatory amino acids and substance $P$ in the mediation of the cough reflex within the nucleus tractus solitarii of the rabbit. Brain Res Bull 74: 284-293, 2007.

50. Nishino T, Hiraga $\mathbf{K}$, Honda $\mathbf{Y}$. Inhibitory effects of $\mathrm{CO}_{2}$ on airways defense reflex responses in enflurane-anaesthetized humans. J Appl Physiol 66: 2642-2646, 1989.

51. Nishino T, Sugimori K, Hiraga K, Honda Y. Influence of CPAP on reflex responses to tracheal irritation in anaesthetized humans. $J$ Appl Physiol 67: 954-958, 1989.

52. Paintal AS. Mechanism of stimulation of J-receptors. J Physiol 203: 511-532, 1969.

53. Phipps PR, Gonda I. Droplets produced by medical nebulizers: some factors affecting their size and solute concentration. Chest 97: 1327-1332, 1990.

54. Poole DC, Ward SA, Whipp BJ. Control of blood-gas and acid-base status during isometric exercise in humans. J Physiol 396, 365-377, 1988.

55. Romaniuk JR, Kowalski KE, Dick TE. The role of pulmonary stretch receptors during cough in dogs. Acta Neurobiol Exp (Warsz) 57: 21-29, 1997.

56. Sackner MA, Watson H, Belsito AS, Feinerman D, Suarez M, Gonzalez G, Bizousky F, Krieger B. Calibration of respiratory inductive plethysmography during natural breathing. J Appl Physiol 66: 410-420, 1989.

57. Sant'Ambrogio G, Sant'Ambrogio F. Reflexes from airway lung, chest wall, and limbs. In: The Lung Scientific Foundation, edited by Crystal RG, West JB. New York: Raven, 1991, p. 1383-1396.

58. Shannon R, Baekey DM, Morris KF, Nuding LS, Segers LS, Lindsey BG. Production of reflex cough by brainstem respiratory networks. Pulm Pharmacol Ther 17: 369-376, 2004.

59. Smith JA, Johnson CM, Brammar CJ, Calam R, Jones S, Woodcock A. The effect of psychological interventions on the urge to cough. Proc Am Thorac Soc 2: A113, 2005.

60. Stirling DR, Cotton DJ, Graham BL, Hodgson WC, Cockroft DW, Dosman JA. Characteristics of airway tone during exercise in patients with asthma. J Appl Physiol 54: 934-942, 1983.

61. Tatar M, Webber SE, Widdicombe JG. Lung C-fibre receptor activation and defensive reflexes in anaesthetized cats. J Physiol 402: 411-420, 1991.

62. Turner DL. Cardiovascular and respiratory control mechanisms during exercise: an integrated view. J Exp Biol 160: 309-340, 1991.

62a.von Euler C. Brain stem mechanisms for generation and control of breathing. In: Handbook of Physiology. The Respiratory System. Control of Breathing. Bethesda, MD: Am Physiol Soc, 1986, sect. 3, vol. II, pt. I, chapt. 1, p. 1-67.

63. Wasserman K, Hansen JE, Sue DY, Casaburi R, Whipp BJ. Principles of exercising testing and interpretation. Philadelphia: Lippincott Williams \& Wilkins, 1999, p. 143-164.

64. Wasserman K, Whipp BJ, Kayla SN, Beaver W. Anaerobic threshold and respiratory gas exchange during gas exchange during exercise. J Appl Physiol 35: 236-243, 1973.

65. Widdicombe JG. Airway receptors. Respir Physiol 125: 3-15, 2001.

66. Widdicombe J, Fontana G, Gibson P. Workshop-Cough: exercise speech and music. Pulm Pharmacol Ther 22: 143-147, 2009.

67. Widdicombe JG, Singh V. Physiological and pathophysiological downregulation of cough. Respir Physiol Neurobiol 150: 105-117, 2006. 